\title{
Characterization and Technological Features of Autochthonous Coagulase-Negative Staphylococci as Potential Starters for Portuguese Dry Fermented Sausages
}

Teresa Semedo-Lemsaddek, Laura Carvalho, Carolina Tempera, Maria H. Fernandes, Maria J. Fernandes, Miguel Elias, António S. Barreto, and Maria J. Fraqueza

\begin{abstract}
The manufacture of dry fermented sausages is an important part of the meat industry in Southern European countries. These products are usually produced in small shops from a mixture of pork, fat, salt, and condiments and are stuffed into natural casings. Meat sausages are slowly cured through spontaneous fermentation by autochthonous microbiota present in the raw materials or introduced during manufacturing. The aim of this work was to evaluate the technological and safety features of coagulase-negative staphylococci (CNS) isolated from Portuguese dry fermented meat sausages in order to select autochthonous starters. Isolates $(n=104)$ obtained from 2 small manufacturers were identified as Staphylococcus xylosus, Staphylococcus equorum, Staphylococcus saprophyticus, and Staphylococcus carnosus. Genomically diverse isolates $(n=82)$ were selected for further analysis to determine the ability to produce enzymes (for example, nitratereductases, proteases, lipases) and antibiotic susceptibility. Autochthonous CNS producing a wide range of enzymes and showing low antibioresistance were selected as potential starters for future use in the production of dry fermented meat sausages.
\end{abstract}

Keywords: antibiorresistance, coagulase-negative staphylococci, fermented meat sausages, starters

Practical Application: Dry fermented sausages' manufacture represents an important segment of the meat industry, especially in Mediterranean countries. Their production, usually occurring in small shops, is based on a spontaneous fermentation by the autochthonous microbiota from raw materials or from environment contamination. The selection of autochthonous starters based on the assessment of their technological properties and susceptibility to antibiotics is of major importance. Safe starters are needed in the meat industry to assure the production of safer meat products while maintaining their particular organoleptic characteristics and subsequent consumers' acceptance.

\section{Introduction}

Dry fermented sausages are a very important part of the meat industry in many countries, especially in the Mediterranean area, where a wide variety of such products is available. The increasing interest in traditional foods is reflected by a growing list of food products registered as PDO (protected designation of origin), PGI (protected geographical indication) or TSG (traditional specialty guaranteed), which promote and protect the names of quality agricultural products and foodstuffs (European commission 2015). Portuguese dry fermented sausages are usually produced by small manufacturers without addition of commercial starters. The products are made from a mixture of pork, fat, salt, water, and different condiments, including garlic and red pepper paste, stuffed into natural casings, slightly fermented and slowly dried by smoking. The microbial population present in traditional fermented sausages is diverse and influenced by the natural microbiota present in the raw

MS 20151975 Submitted 11/27/2015, Accepted 3/21/2016. Authors SemedoLemsaddek, Carvalho, Tempera, Fernandes, Fernandes Barreto, and Fraqueza are with Centro de Investigação Interdisciplinar em Sanidade Animal, Faculdade de Medicina Veterinária, Univ. Técnica de Lisboa, Avenida da Univ. Técnica, 1300-477, Lisboa, Portugal. Author Elias is with Univ. de Évora, Inst. de Ciências Agrárias e Ambientais Mediterrânicas, Apartado 94, 7002-554, Évora, Portugal. Direct inquiries to author Fraqueza (E-mail: mjoaofraqueza@fmv.ulisboa.pt). materials, temperature, $\mathrm{pH}$, and water activity during the fermentation process. Ripening of such products induces specific texture, color, flavor, and organoleptic characteristics, which led to the inclusion of Portuguese dry fermented sausages in a collection of delicacies known worldwide (Talon and others 2012).

The quality of a product is closely related to the ripening process and spontaneous fermentation is known to rely on the participation of lactic acid bacteria (LAB) and coagulase-negative staphylococci (CNS). Such high microbial counts are probably related with the slaughtering process, where bacteria present on the skin of warm-blooded animals are disseminated to the raw material - minced raw pork (Marty and others 2012a). The most abundant CNS present in naturally fermented sausages are Staphylococcus xylosus, Staphylococcus saprophyticus, Staphylococcus equorum, and Staphylococcus carnosus (Janssens and others 2012; Marty and others 2012a). These bacteria reduce nitrates to nitrites, contributing to the formation of nitrosomyoglobin and the characteristic pink-red color in the product. CNS also produce proteases and lipases, the enzymes involved in the formation of various aromatic substances and organic acids, which confer distinct organoleptic properties (Simonová and others 2006; Talon and Leroy 2011).

In order to preserve the specificities of Portuguese dry fermented sausages, it is important to select autochthonous bacteria for use as starter cultures. Indigenous microorganisms, also known 
as "in house flora," are well adapted to particular products and manufacturing processes. Therefore, their use as starter cultures for the traditional production of fermented sausages may allow the manufacture of more homogeneous products in terms of safety and preservation of the original qualities. In this context, the aim of this study was to isolate and identify staphylococci from Portuguese traditional dry fermented meats, evaluating their technologies features and safety, for the selection of potential meat starter cultures.

\section{Materials and Methods}

\section{Microbial analysis}

Sampling. For the present investigation we studied 2 smallmanufacturers in Alentejo, a Southern region of Portugal, coded A and B. Samples were collected from Portuguese dry fermented sausage "chouriço"; including raw material (minced pork meat), secondary ingredients (for example, garlic, red pepper paste and natural casings), product after a resting period and stuffing, and final product, as well as production tools (for example, knifes, tables, mincing and stuffing machines). All the samples were obtained after routine disinfection procedures, in both manufactures.

Bacterial isolation. After transport to the laboratory in refrigerated boxes, all surfaces, food and ingredients samples were prepared according to ISO 18593 (2004) and Talon and others (2007, 2012). Decimal dilutions of the homogenate were prepared with sterile Ringer solution, plated on Manitol Salt Agar (MSA) (Scharlau, Barcelona, Spain) and incubated at $37{ }^{\circ} \mathrm{C}$ for $48 \mathrm{~h}$. Single colonies were randomly picked from MSA plates and further purified by streaking on Tryptone Salt Agar (TSA) (Scharlau, Spain) incubated for $2 \mathrm{~d}$ at $37^{\circ} \mathrm{C}$. Isolates were grown in Brain Heart Infusion (BHI) (Scharlau, Spain) and maintained at $-80{ }^{\circ} \mathrm{C}$ in BHI with $20 \%$ glycerol.

Genus and species allocation. Identification at species level was performed both by phenotypic and genotypic methodologies. Isolates were submitted to Gram staining, oxidase, catalase, and coagulase tests. Presumptive CNS were further analyzed by API-STAPH galleries (BioMérieux, Linda-a-Velha, Portugal), and submitted to molecular identification. DNA was obtained using the QIAamp DNA mini kit (Qiagen, Quilaban, Sintra, Portugal) and PCR amplification performed using Staphylococcus-specific primers Tstag765/TstaG42, S. saprophyticusspecific primers Sap1/Sap2, S. epidermidis-specific primers Se705$1 /$ Se705-2, S. aureus-specific primers Sa442-1/Sa442-2 and S. xylosus-specific primers XYLF/XYLR, developed by MorotBizot and others (2003). Regarding staphylococcal species $S$. equorum and $S$. carnosus, oligonucleotides applied for molecular identification were, respectively, SdAEqF/SdAEqR (Blaiotta and others 2004) and carF/carR (Blaiotta and others 2005).

Amplification mixtures were prepared as follows: $1 \mathrm{X}$ reaction buffer, $0.2 \mathrm{mM}$ of each deoxynucleoside triphosphate, $2.5 \mathrm{mM}$ $\mathrm{MgCl}_{2}, 0.5 \mu \mathrm{M}$ of each primer, $1 \mathrm{U}$ of Taq DNA polymerase (NZYTech, Lisboa, Portugal) and $100 \mathrm{ng}$ of DNA. Thermocycler conditions were $3 \mathrm{~min}$ at $94{ }^{\circ} \mathrm{C}, 40$ cycles of $30 \mathrm{~s}$ at $95{ }^{\circ} \mathrm{C}$, $30 \mathrm{~s}$ at $55^{\circ} \mathrm{C}, 30 \mathrm{~s}$ at $72{ }^{\circ} \mathrm{C}$ and a final hold of $3 \mathrm{~min}$ at $72{ }^{\circ} \mathrm{C}$. Ten microliters of each PCR product were combined with $2 \mu \mathrm{L}$ of loading buffer and resolved by agarose gel electrophoresis $(1 \%$ $\mathrm{w} / \mathrm{v}$ ) in $0.5 \mathrm{X} \mathrm{TBE}$ buffer at $95 \mathrm{~V}$ for $1 \mathrm{~h} 30 \mathrm{~min}$. After staining with ethidium bromide, agarose gels were photographed on ImageMaster (Pharmacia Biotech, GE Healthcare, Buckinghamshire, UK).

Staphylococcus epidermidis ATTC RP62A, S. saprophyticus DSMZ 18669, S. aureus ATTC 29213, S. xylosus ATTC 8166, S. carnosus
DSMZ 4600, and S. equorum DSMZ 20029 were used as control strains in all PCR amplification procedures.

Genomic typing. PCR fingerprinting was performed using the primer OPC19 $\left(5^{\prime}-\mathrm{GTTGCCAGCC}-3^{\prime}\right)$ in $0.2 \mathrm{~mL}$ reaction tubes with mixtures containing: $1 \mathrm{X}$ reaction buffer, $0.2 \mathrm{mM}$ of each deoxynucleoside triphosphate, $2.5 \mathrm{mM} \mathrm{MgCl}_{2}, 0.5 \mu \mathrm{M}$ primer, 2 U of Taq DNA polymerase (NZYTech, Portugal) and $100 \mathrm{ng}$ of DNA. Thermocycler conditions were as follows: initial step of $94^{\circ} \mathrm{C}$ for $4 \mathrm{~min}, 40$ cycles with $1 \mathrm{~min}$ at $94{ }^{\circ} \mathrm{C}, 2 \mathrm{~min}$ at $40^{\circ} \mathrm{C}$ and $2 \mathrm{~min}$ at $72{ }^{\circ} \mathrm{C}$, plus an additional step at $72{ }^{\circ} \mathrm{C}$ for 10 min for chain elongation. Ten microliters of each PCR product were combined with $2 \mu \mathrm{L}$ of loading buffer and resolved by agarose gel electrophoresis $(1.5 \% \mathrm{w} / \mathrm{v})$ in $0.5 \mathrm{X}$ TBE buffer at $80 \mathrm{~V}$ for $3 \mathrm{~h}$. After staining with ethidium bromide, agarose gels were photographed on ImageMaster (Pharmacia Biotech, GE Healthcare, UK). The BioNumerics software (version 6.6, Applied Maths, Kortrijk, Belgium) was used to register PCR fingerprinting patterns, normalize densitometric traces, calculate Pearson productmoment correlation coefficient and perform cluster analysis by the UPGMA algorithm.

\section{Technological features}

Nitrate reduction. Nitrate reductase activity was tested in BHI plates inoculated with $10 \mu \mathrm{L}$ of a standardized inoculum (OD600 of 0.8 to 1.0 ) followed by incubation at $15{ }^{\circ} \mathrm{C}$ for $72 \mathrm{~h}$. After growth the plate was flooded with NIT1:NIT2 (Sulfanilic acid: N,N-Dimethyl-1-naphthylamine; BioMérieux, Portugal) which led to the development of a purple halo around the nitrate reducing strains. According to the diameter of the halo the isolates were classified as low (1), medium (2), or strong (3) nitrate reducers.

Proteolytic and lipolytic activities. Enzymatic activities were evaluated by plate inoculation using $10 \mu \mathrm{L}$ of a standardized inoculum (OD600 of 0.8 to 1.0). Gelatinase activity was detected using 3\% gelatin medium (Ribeiro and others 2011), after incubation for $48 \mathrm{~h}$ at $37^{\circ} \mathrm{C}$ plates were flooded with a saturated solution of ammonium sulphate and gelatonolytic strains showed a transparent halo around the colonies. Lipase activity was detected with Spirit Blue agar (Difco, Oxford, England) supplemented with sterile pork fat, colonies of lipolytic organisms were recognized by development of a dark-blue color and translucent beneath and surrounding the colonies after $48 \mathrm{~h}$ growth at $37^{\circ} \mathrm{C}$.

Enzymatic profiles by API-ZYM analysis. Selected staphylococci were tested using API ZYM galleries (BioMérieux, Portugal) as described by the manufacturer. Briefly, strains were grown on BHI plates at $37^{\circ} \mathrm{C}$ overnight, the cell mass removed from the surface of the plate and ressuspended in $2 \mathrm{~mL}$ of distilled water, to produce a dense suspension, which was used to inoculate the cupules of API-ZYM strips. After $4 \mathrm{~h}$ incubation at $37{ }^{\circ} \mathrm{C}$ in moist atmosphere the reactions were terminated by addition of the API-ZYM reagents and classified according to the color chart provided by the manufacturer.

Safety assessment: antimicrobial susceptibility testing. Susceptibility to 6 antimicrobial agents (ampicillin - $10 \mu \mathrm{g}$, erythromycin - $15 \mu \mathrm{g}$, penicillin $\mathrm{G}-10 \mathrm{U}$, gentamicin $-10 \mu \mathrm{g}$, tetracycline $-30 \mu \mathrm{g}$, and vancomycin $-30 \mu \mathrm{g}$ ) was tested by the disk diffusion method using breakpoints of resistance previously established by the National Committee for Clinical Laboratory Standards (2013). S. aureus ATCC 25923 was used for quality control.

The reproducibility level of all the methodologies applied was assessed by analyzing a random sample of $10 \%$ duplicates. 


\section{Results and Discussion}

\section{Isolation, identification, and genomic diversity}

Portuguese traditional varieties of fermented pork sausages are different from related products in various aspects: meat products are prepared with singular condiments and following particular know-how. The meat is minced, mixed with spices, salt and nitrite; the stuffed sausages are ripen 1 to $3 \mathrm{~d}$, smoked and cured for a minimum of 4 to $8 \mathrm{wk}$, at temperatures below $15{ }^{\circ} \mathrm{C}$, depending of their diameter. Since distinctive organoleptic features can be attributed to traditional dry smoked fermented sausages produced in specific regions, it is fundamental to characterize the technologically important microbiota present in each environmental site point/product and select putative autochthones-starters to ensure a more standardized fermentation, reduce the curing period, improve product safety and enhance flavor (Bonomo and others 2009; Cachaldora and others 2013). Due to the importance of staphylococci in the development of sensory properties (flavor, texture, and color) of fermented sausages by reduction of nitrates, proteolytic, and lipolytic activities (Talon and others 2008; Bonomo and others 2009) these bacteria constitute eligible candidates. However, potential starters have to comply with rigorous selection criteria based on the assessment of technological features and overall safety (Leroy and others 2006; Ammor and Mayo 2007; Talon and Leroy 2011), as evaluated in this study.

In this study, a total of 104 isolates were recovered from the 2 small-manufacturers (A, B), either from raw/meat-products or food contact surfaces. Subsequent identification, using phenotypic and genotypic methodologies, identified the isolates as follows: 37 S. xylosus $(\mathrm{A}=31, \mathrm{~B}=6), 21$ S. equorum $(\mathrm{A}=5, \mathrm{~B}=16), 14$ S. saprophyticus $(\mathrm{A}=4, \mathrm{~B}=10)$, and 9 S. carnosus $(\mathrm{A}=8, \mathrm{~B}=1)$; whereas 23, although confirmed as members of the Staphylococcus genus, could not be identified at the species level.

The presence of high CNS counts has been reported for meat fermented sausages from various origins (Morot-Bizot and others 2006; Simonová and others 2006; Drosinos and others 2007; Gounadaki and others 2008; Bonomo and others 2009; Janssens and others 2012; Marty and others 2012b; Cachaldora and others 2013; Landeta and others 2013; Połka and others 2015), although species identification and relative quantities may vary from country to country. S. xylosus, S. equorum, S. saprophyticus, and S. carnosus are among the prevalent species.

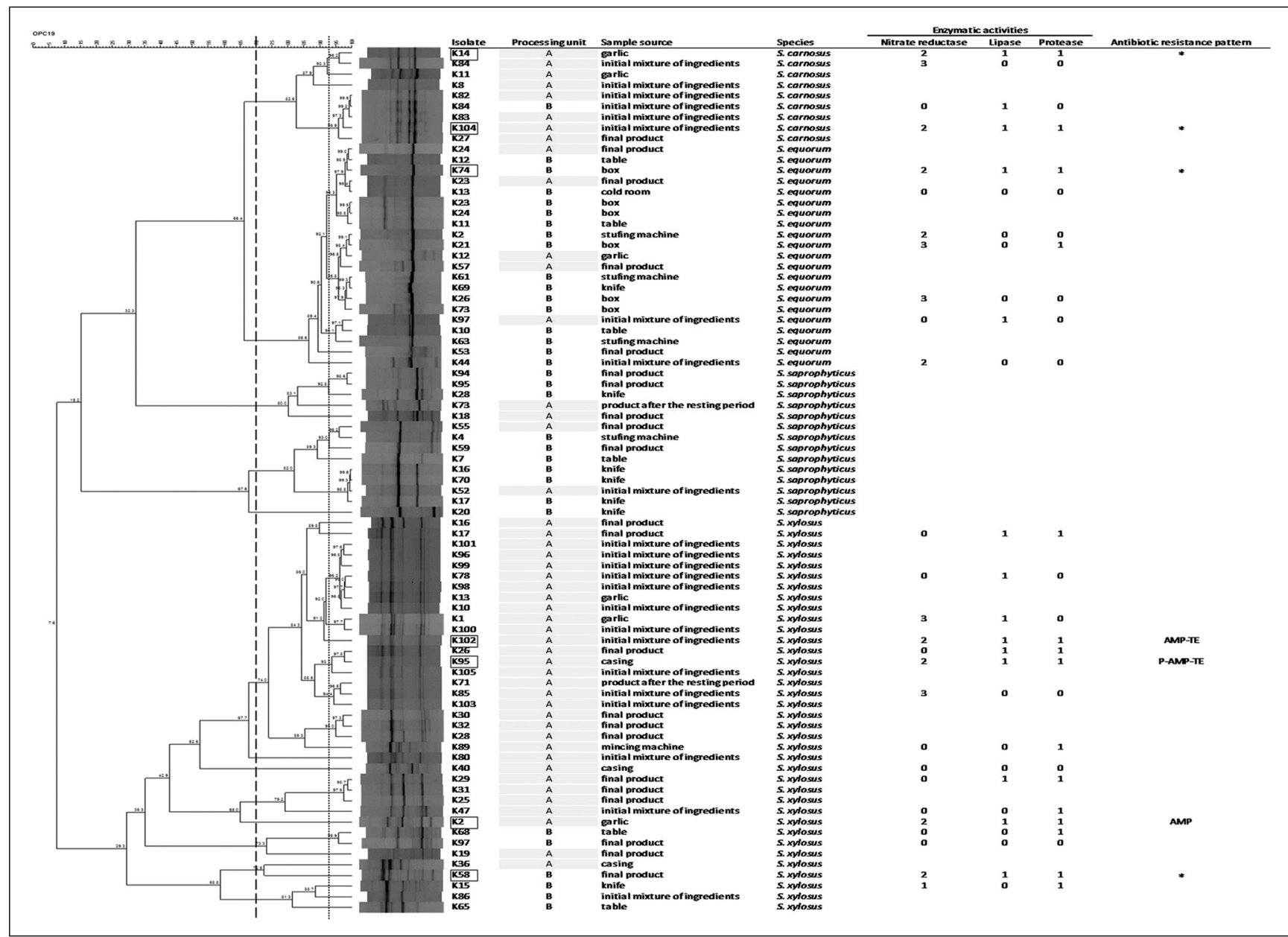

Figure 1-Dendrogram based on PCR-fingerprinting patterns with primer OPC19. The composed image also displays information on isolates origin (manufacturer A or B), sample source and species, enzymatic abilities and antibiotic resistance profiles. Similarity was calculated with Pearson productmoment correlation coefficient $(r)$ and clustering was performed with UPGMA. The round-doted-line represents the reproducibility level (93\%), the cut-off level of $70 \%$, used to define genomic-types, is represented by a dashed-line and the coagulase-negative staphylococci selected for further analysis are highlighted by a black rectangle. Scores $0,1,2$, and 3 correspond, respectively to no enzymatic activity, weak activity, moderate activity, and strong activity. AMP corresponds to ampicillin, TE to tetracycline, and P to penicillin. The stars mean that, although tested, no antibiotic resistances were observed. 
Table 1-Enzymatic patterns of the isolates determined with the API-ZYM system.

\begin{tabular}{|c|c|c|c|c|c|c|c|}
\hline \multirow[b]{3}{*}{ Enzymatic activities } & \multicolumn{7}{|c|}{ Processing units } \\
\hline & \multicolumn{5}{|c|}{ A } & \multicolumn{2}{|c|}{ B } \\
\hline & K2 & K14 & K95 & K102 & K104 & K58 & K74 \\
\hline Alkaline phosphatase & 5 & 1 & 5 & 5 & 2 & 1 & 5 \\
\hline Esterase (C4) & 3 & 0 & 5 & 3 & 4 & 4 & 4 \\
\hline Esterase lipase (C8) & 4 & 1 & 5 & 3 & 3 & 4 & 4 \\
\hline Lipase (C14) & 2 & 0 & 0 & 1 & 1 & 1 & 0 \\
\hline Leucine arylamidase & 1 & 1 & 1 & 0 & 4 & 1 & 1 \\
\hline Valine arylamidase & 1 & 0 & 1 & 0 & 1 & 1 & 1 \\
\hline Cysteine arylamidase & 2 & 2 & 2 & 3 & 3 & 2 & 3 \\
\hline Trypsin & 0 & 0 & 1 & 0 & 0 & 0 & 0 \\
\hline$\alpha$-Chymotrypsin & 0 & 0 & 1 & 0 & 1 & 0 & 0 \\
\hline Acid phosphatase & 4 & 5 & 3 & 4 & 5 & 0 & 4 \\
\hline Napthol-AS-BI-phosphohydrolase & 2 & 2 & 4 & 3 & 2 & 2 & 2 \\
\hline$\alpha$-Galactosidase & 1 & 0 & 0 & 0 & 1 & 0 & 1 \\
\hline$\beta$-Galactosidase & 2 & 0 & 2 & 2 & 0 & 1 & 1 \\
\hline$\beta$-Glucoronidase & 0 & 0 & 1 & 2 & 0 & 0 & 0 \\
\hline$\alpha$-Gluconidase & 2 & 0 & 0 & 0 & 0 & 0 & 1 \\
\hline$\beta$-Gluconidase & 2 & 0 & 0 & 0 & 1 & 0 & 5 \\
\hline N-Acetyl-a-glucosaminidase & 0 & 1 & 0 & 0 & 0 & 2 & 0 \\
\hline$\alpha$-Mannosidase & 1 & 0 & 0 & 0 & 0 & 0 & 1 \\
\hline$\alpha$-Fucosidase & 1 & 0 & 0 & 0 & 0 & 0 & 1 \\
\hline
\end{tabular}

Scores 1 to 5 correspond to increasing enzymatic activities ( 1 being the lowest and 5 the highest).

In order to assess for the genomic diversity of the 81 meat-related staphylococci, the isolates were submitted to PCR amplification using the random primer OPC-19. The BioNumerics software was used to build a dendrogram based on the fingerprinting patterns (Figure 1). The reproducibility level of $93 \%$, estimated based on the similarity observed between the fingerprinting patterns of $10 \%$ random replicates and the corresponding original profiles, is represented by a round-doted-line. Global analysis of the dendrogram shows clustering of the isolates according to species and further demonstrates the prevalence of the species $S$. xylosus in the processing unit A, while $S$. equorum were mostly found in processing unit B. Furthermore, results also showed high levels of similarity between staphylococci recovered from distinct manufacturers (for example, A-K82 = B-K84; A-K97 = B-K10) and sampled products (for example, A-K12garlic = A-K57final product; $\mathrm{B}$ $\mathrm{K} 13$ cold room $=\mathrm{B}-\mathrm{K} 23 \mathrm{box}=\mathrm{B}-\mathrm{K} 11$ table), pointing toward the presence of specific strains in the raw materials and/or to their persistence in the manufacturing settings. These results point toward the presence/importance of a characteristic in house microbiota in the processing units studied. The role of indigenous microorganisms in meat fermentations has already been mentioned in several previous reports (Santos and others 1998; Benito and others 2007; Gounadaki and others 2008; Fonseca and others 2013; Landeta and others 2013; Połka and others 2015).

Visual analysis of the dendrogram led to the selection of the cutoff level of $70 \%$ (represented by a dashed-line), isolates grouping at similarity levels equal or above this value were considered highly related. This approach was used select representative staphylococci $(n=27)$ for the subsequent evaluation of technological features and overall safety. Due to the pathogenicity potential associated with S. saprophyticus (Rosenstein and Götz 2013), meat isolates belonging to that species were also eliminated from further analysis.

Evaluation of desirable technological features was based on the assessment of nitrate reduction, proteolytic and lipolytic abilities and determination of enzymatic profiles using API-ZYM galleries.

Results obtained for nitrate reduction, proteolytic and lipolytic activities are displayed in Figure 1. Regarding nitrate reduction, 5 isolates were considered high, 9 medium and 1 low ni- trate reducers; while twelve CNS did not demonstrate this ability. Color development and stability are very important quality features of fermented meat products. The formation of the nitrosomyoglobin pigment, responsible for the characteristic bright red color is a property that is enhanced by nitrate-reducer microorganisms present during the manufacturing process (Gøtterup and others 2008). Hence, isolates to be selected as autochthone-starters must harbor this trait, since bacteria with nitrate-reductase activity lead to a significantly faster rate of pigment formation. Furthermore, nitrate reduction produces nitrite, which can limit lipid oxidation (Talon and others 1999). Proteolytic and lipolytic abilities are also essential, due to the high protein and lipid content of the meat. Among the CNS, fourteen shown to be lipolytic, while fifteen produced proteases. These properties have already been described in previous reports (Miralles and others 1996; Lopes and others 1999; Casaburi and others 2006; Abriouel and others 2012) and associated with the development of organoleptic properties, such as texture and flavor.

The simultaneous nitrate-reduction, lipolytic and proteolytic activities were observed for 7 of the isolates under analysis (highlighted in Figure 1 by a rectangle), which were further analyzed regarding their enzymatic profiles by API-ZYM and susceptibility to 6 antimicrobial agents.

Enzymatic profiles of the 7 isolates, 5 from processing unit $A$ and 2 from processing unit B, are presented in Table 1. Evaluation of the technological features of the meat-staphylococci showed their ability to produce a wide spectrum of enzymes, which points to their importance in the manufacture of traditional fermented sausages.

Overall, the CNS studied exhibited low proteinase (trypsin and chymotrypsin) and high peptidase (leucine, valine, and cysteine aminopeptidase) activities, which is a desirable quality in the ripening and production of some typical food flavors (Thapa and others 2006; Ben and others 2009). The metabolic versatility of the CNS under study can help highlight their importance in the production of fermented meat products, as well as their persistence in the processing units under analysis. However, the use of bacteria in the food industry also depends on their safety 
(Even and others 2010; Marty and others 2012a; Fraqueza 2015) therefore, the meat-staphylococci under analysis were further analyzed regarding antibiotic susceptibility. Results displayed in Figure 1 shown that all selected CNS were susceptible to erythromycin, gentamycin, and vancomycin, 3 were considered resistant to ampicillin, 2 to tetracycline and 1 to penicillin.

Overall, combination of all the results obtained along this study points to isolates $\mathrm{K} 2$ (S. xylosus) from processing unit A and K74 (S. equorum) from processing unit $\mathrm{B}$ as potential starters. These meat CNS belong to the species predominant in each unit, reduce nitrate, produce a wide array of enzymes and present susceptibility to the majority of the antimicrobials tested. Hence, aforementioned staphylococci can be considered reliable candidates for future use in the manufacture of dry smoked fermented sausages in the studied processing units.

\section{Conclusions}

Our results showed a wide diversity among staphylococci isolated from traditional fermented sausages and processing environment in the Southern region of Portugal, Alentejo. The microbiota present in the sampled sites was characterized by the predominance of S. xylosus in processing unit A and S. equorum in processing unit $\mathrm{B}$, which suggests high adaptation skills of these bacteria to particular ecological niches.

Evaluation of technological and safety features led to the selection of 2 meat-staphylococci for further use as autochthonestarters, as alternative to commercial-starters that do not always give satisfactory results in the production process, especially regarding the preservation of typical organoleptic and sensory characteristics. Further studies should be carried out to evaluate the effectiveness of selected microorganisms in meat-model and experimental processing of sausages to observe the evolution of the microbiota present and the process parameters affected by the inclusion of these native starters.

\section{Acknowledgments}

This study was performed on "Centro de Investigação Interdisciplinar em Sanidade Animal" (CIISA/FMV) from Faculdade de Medicina Veterinária da Univ. de Lisboa (Faculty of Veterinary Medicine, Univ. of Lisbon), through Project UID/CVT/00276/2013 from "Fundação para a Ciência e Tecnologia". This study also had the financial support of project "Portuguese traditional meat products: strategies to improve safety and quality" (PTDC/AGR-ALI/119075/2010), by Fundação para a Ciência e a Tecnologia (FCT). Teresa Semedo-Lemsaddek was financially supported by Program "Ciência" from FCT.

\section{References}

Abriouel H, Benomar N, Cobo A, Caballero N, Fernández Fuentes M Á, Pérez-Pulido R, Gálvez A. 2012. Characterization of lactic acid bacteria from naturally-fermented Manzanill Aloreña green table olives. Food Microbiol 32(2):308-16. doi:10.1016/j.fm.2012.07.006

Ammor M, Mayo B. 2007. Selection criteria for to be used as functional starter cultures in dry sausage production: An update. Meat Sci 76:138-46. doi:10.1016/j.meatsci.2006.10.022

Ben Belgacem Z, Dousset X, Prévost H, Manai M. 2009. Polyphasic taxonomic studies of lactic acid bacteria associated with Tunisian fermented meat based on the heterogeneity of the 16S-23S rRNA gene intergenic spacer region. Arch Microbiol 191(9):711-20. doi:10.1007/s00203-009-0499-2

Benito MJ, Martín A, Aranda E, Pérez-Nevado F, Ruiz-Moyano S, Córdoba MG. 2007 Characterization and selection of autochthonous lactic acid bacteria isolated from traditional Iberian dry-fermented salchichón and chorizo sausages. J Food Sci 72(6):M193-201. doi:10.1111/j.1750-3841.2007.00419.x

Blaiotta G, Ercolini D, Mauriello G, Salzano G, Villani F. 2004. Rapid and reliable identification of Staphylococcus equorum by a species-specific PCR assay targeting the sodA gene. Syst Appl Microbiol 27(6):696-702. doi:10.1078/0723202042369901

Blaiotta G, Casaburi A, Villani F. 2005. Identification and differentiation of Staphylococcus carnosus and Staphylococcus simulans by species-specific PCR assays of sod A genes. Syst Appl Microbiol 28:519-26. doi:10.1016/j.syapm.2005.03.007
Bonomo MG, Ricciardi A, Zotta T, Sico MA, Salzano G. 2009. Technological and safety characterization of coagulase-negative staphylococci from traditionally fermented sausages of Basilicata region (Southern Italy). Meat Sci 83(1):15-23. doi:10.1016/j.meatsci.2009.03.006 Cachaldora A, Fonseca S, Franco I, Carballo J. 2013. Technological and safety characteristics of Staphylococcaceae isolated from Spanish traditional dry-cured sausages. Food Microbiol 33(1):61-8. doi:10.1016/j.fm.2012.08.013

Casaburi A, Villani F, Toldrá F, Sanz Y. 2006. Protease and esterase activity of staphylococci. Intl J Food Microbiol 112(3):223-9. doi:10.1016/j.ijfoodmicro.2006.04.008

Clinical and Laboratory Standards Institute (CLSI). 2013. Performance Standards for Antimicrobial Susceptibility Testing 23rd Informational Supplement. CLSI=NCCLS M100-S23. Clinical and Laboratory Standards Institute, Wayne, Pa.

Drosinos EH, Paramithiotis S, Kolovos G, Tsikouras I, Metaxopoulos I. 2007. Phenotypic and technological diversity of lactic acid bacteria and staphylococci isolated from traditionally fermented sausages in Southern Greece. Food Microbiol 24:260-70. doi:10.1016/j.fm.2006.05.001

Even S, Leroy S, Charlier C, Zakour NB, Chacornac JP, Lebert I, Jamet E, Desmonts MH, Coton E, Pochet S, Donnio PY, Gautier M, Talon R, Le Loir Y. 2010. Low occurrence of safety hazards in coagulase negative staphylococci isolated from fermented foodstuffs. Intl J Food Microbiol 139(1-2):87-95. doi:10.1016/j.ijfoodmicro.2010.02.019

European Commission. 2015. Geographical indications and traditional specialities, Quality Policy. Agriculture and rural development. Available from: http://ec.europa. eu/agriculture/quality/schemes/index_en.htm. Accessed 2015 October 12.

Fonseca S, Ivette Ouoba LI, Franco I, Carballo J. 2013. Use of molecular methods to characterize the bacterial community and to monitor different native starter cultures throughout the ripening of Galician chorizo. Food Microbiol 34(1):215-26. doi:10.1016/j.fm.2012.12.006

Fraqueza MJ. 2015. Antibiotic resistance of lactic acid bacteria isolated from dryfermented sausages. Intl J Food Microbiol, pii: S0168-1605(15)00238-X. doi: 10.1016/j. ijfoodmicro.2015.04.035

Gøtterup J, Olsen K, Knøchel S, Tjener K, Stahnke LH, Møller JKS. 2008. Colour formation in fermented sausages by meat-associated staphylococci with different nitrite- and nitratereductase activities. Meat Sci 78:492-501. doi:10.1016/j.meatsci.2007.07.023

Gounadaki AS, Skandamis PN, Drosinos EH, Nychas GJE. 2008. Microbial ecology of food contact surfaces and products of small-scale facilities producing traditional sausages. Food Microbiol 25(2):313-23. doi:10.1016/j.fm.2007.10.001

ISO 18593: 2004. Microbiology of food and animal feeding stuffs-horizontal methods for sampling techniques from surfaces using contact plates and swabs. International Standard Organization, Geneva, Switzerland, p.8.

Janssens M, Myter N, De Vuyst L, Leroy F. 2012. Species diversity and metabolic impact of the microbiota are low in spontaneously acidi fi ed Belgian sausages with an added starter culture of Staphylococcus carnosus. Food Microbiol 29(2):167-77. doi:10.1016/j.fm.2011.07.005

Landeta G, Curiel JA, Carrascosa AV, Muñoz R, Rivas BDE. 2013. Characterization of coagulase-negative staphylococci isolated from Spanish dry cured meat products. Meat Sci 93(3):387-96. doi:10.1016/j.meatsci.2012.09.019

Leroy F, Verluyten J, De Vuyst L. 2006. Functional meat starter cultures for improved sausage fermentation. Int J Food Microbiol 106(3):270-85. doi:10.1016/j.ijfoodmicro.2005.06.027

Lopes MF, Cunha AE, Clemente JJ, Carrondo MJ, Crespo MT. 1999. Influence of environmental factors on lipase production by Lactobacillus plantarum. Appl Microbiol 51(2):249-54. Marty E, Bodenmann C, Buchs J, Hadorn R, Eugster-meier E, Lacroix C, Meile L. 2012a. Prevalence of antibiotic resistance in coagulase-negative staphylococci from spontaneously fermented meat products and safety assessment for new starters. Intl J Food Microbiol 159(2):7483. doi:10.1016/j.ijfoodmicro.2012.07.025

Marty E, Buchs J, Eugster-Meier E, Lacroix C, Meile L. 2012b. Identification of staphylococci and dominant lactic acid bacteria in spontaneously fermented Swiss meat products using PCR-RFLP. Food Microbiol 29(2):157-66. doi:10.1016/j.fm.2011.09.011

Miralles MC, Flores J, Perez-Martinez G. 1996. Biochemical tests for the selection of Staphylococcus strains as potential meat starter cultures. Food Microbiol 13(3):227-36. doi:10.1006/fmic. 1996.0028

Morot-Bizot S, Talon R, Leroy-Setrin S. 2003. Development of specific PCR primers for a rapid and accurate identification of Staphylococcus xylosus, a species used in food fermentation. J Microbiol Meth 55(1):279-86. doi:10.1016/S0167-7012(03)00159-3

Morot-Bizot SC, Leroy S, Talon R. 2006. Staphylococcal community of a small unit manufacturing traditional dry fermented sausages. Intl J Food Microbiol 108:210-17. doi:10.1016/j.ijfoodmicro.2005.12.006

Połka J, Rebecchi A, Pisacane V, Morelli L, Puglisi E. 2015. Bacterial diversity in typical Italian salami at different ripening stages as revealed by high-throughput sequencing of $16 \mathrm{~S}$ rRNA amplicons. Food Microbiol 46:342-56. doi:10.1016/j.fm.2014.08.023

Ribeiro T, Oliveira M, Fraqueza MJ, Lauková A, Elias M, Tenreiro R, Barreto AS, SemedoLemsaddek T. 2011. Antibiotic resistance and virulence factors among Enterococci isolated from chouriço, a traditional Portuguese dry fermented sausage. J Food Prot 74(3):465-9. doi:10.4315/0362-028X.JFP-10-309

Rosenstein R, Götz F. 2013. What distinguishes highly pathogenic staphylococci from mediumand non-pathogenic? Curr Top Microbiol Immunol 358:33-89. doi: 10.1007/82_2012_286

Santos EM, González-Fernández C, Jaime I, Rovira J. 1998. Comparative study of lactic acid bacteria house flora isolated in different varieties of "chorizo." Intl J Food Microbiol 39 (1-2):123-28. doi:10.1016/S0168-1605(97)00128-1

Simonová M, Strompfová V, Marciňáková M, Lauková A, Vesterlund S, Moratalla ML, Bover-Cid S, Vidal-Carou C. 2006. Characterization of Staphylococcus xylosus and Staphylococcus carnosus isolated from Slovak meat products. Meat Sci 73(4):559-64 doi:10.1016/j.meatsci.2006.02.004

Talon R, Leroy S. 2011. Diversity and safety hazards of bacteria involved in meat fermentations. Meat Sci 89(3):303-9. doi:10.1016/j.meatsci.2011.04.029

Talon R, Walter D, Chartier S, Barrière C, Montel MC. 1999. Effect of nitrate and incubation conditions on the production of catalase and nitrate reductase by staphylococci. Intl J Food Microbiol 52(1-2):47-56. doi:10.1016/S0168-1605(99)00127-0

Talon R, Lebert I, Lebert A, Leroy S, Garriga M, Aymerich T, Drosinos EH, Zanardi E, Ianieri A, Fraqueza MJ, Patarata L, Lauková A. 2007. Traditional dry fermented sausages produced in small-manufacturers in Mediterranean countries and Slovakia. 1. Microbial ecosystems of processing environments. Meat Sci 77: 570-79

Talon R, Leroy S, Lebert I, Giammarinaro P, Chacornac JP, Latorre-Moratalla M, Vidal-Carou C, Zanardi E, Conter M, Lebecque A. 2008. Safety improvement and preservation of typical 
sensory qualities of traditional dry fermented sausages using autochthonous starter cultures. Int J Food Microbiol 126(1-2):227-34. doi:10.1016/j.ijfoodmicro.2008.05.031

Talon R, Lebert I, Lebert A, Leroy S, Garriga M, Aymerich T, Drosinos EH, Zanardi

E, Ianieri A, Fraqueza MJ, Patarata L, Laukova A. 2012. Microbial ecosystem of traditional dry fermented sausages in Mediterranean countries and Slovakia. In: Gina S.

Williams, editor. Mediterranean ecosystems: dynamics, management and conservation.

Earth Sciences in the 21st Century Environmental Science, Engineering and Technol- ogy. Nova Science Publishers Inc. ISBN: 978-1-61209-146-4. pp. 115-128. https://www. novapublishers.com/catalog/product_info.php?products_id $=36256$

Thapa N, Pal J, Tamang JP. 2006. Phenotypic identification and technological properties of lactic acid bacteria isolated from traditionally processed fish products of the Eastern Himalayas. Intl J Food Microbiol 107(1):33-8. doi:10.1016/j.ijfoodmicro.2005.08.009 